\title{
Comparative study of low power wide area network based on internet of things for smart city deployment in Bandung city
}

\author{
Muhammad Imam Nashiruddin ${ }^{1,2}$, Maruli Tua Baja Sihotang', Muhammad Ary Murti ${ }^{1}$ \\ ${ }^{1}$ School of Electrical Engineering, Telkom University, Bandung, Indonesia \\ ${ }^{2}$ Peruri Research Institute for Authenticity (PRIfA), The Indonesian Government Security Printing and Minting Corporation \\ (PERUM PERURI), Jakarta, Indonesia
}

\begin{tabular}{l} 
Article Info \\
\hline Article history: \\
Received Dec 21, 2020 \\
Revised Dec 3, 2021 \\
Accepted Dec 10, 2021 \\
\hline
\end{tabular}

Keywords:

Long-range wide area network Low power wide area network Narrow-band internet of things Network planning

Random phase multiple access Smart city

\begin{abstract}
Smart city implementation, such as smart energy and utilities, smart mobility \& transportation, smart environment, and smart living in urban areas is expanding rapidly worldwide. However, one of the biggest challenges that need to be solved is the selection of the appropriate internet of things (IoT) connectivity technologies. This research will seek for the best candidate low power wide area network (LPWAN) technologies such as long-range wide area network (LoRaWAN), narrow-band internet of things (NB-IoT), and random phase multiple access (RPMA) for IoT smart city deployment in Bandung city is based on IoT network connectivity between with six technical evaluation criteria: gateway requirements, traffic/data projection, the best signal level area distribution, and overlapping zones. Bass model is carried out to determine the capacity forecast. While in coverage prediction, LoRaWAN and NB-IoT use the Okumura-Hata propagation, and ErcegGreenstein (SUI) model is used for RPMA. Based on the simulation and performance evaluation results, RPMA outperforms LoRaWAN and NBIoT. It required the least gateway number to cover Bandung city with the best signal levels and overlapping zones.
\end{abstract}

This is an open access article under the CC BY-SA license.

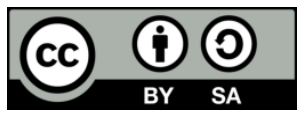

\section{Corresponding Author:}

Muhammad Imam Nashiruddin

School of Electrical Engineering, Telkom University

Telekomunikasi Terusan Buah Batu Indonesia Street, 40257, Bandung, Indonesia

Email: imamnashir@telkomuniversity.ac.id

\section{INTRODUCTION}

Smart city is a concept of urban development consisting of economic, social, and environmental aspects that focus on citizens' quality of life. Health aging and welfare, energy, transportation, and the environment, an inclusive, innovative, reflective, and safe society will become global social challenges and even Indonesia. Information and communication technology (ICT) is the primary technology behind the smart city complex's development. Intelligent systems that connect things and the information world and provide an autonomous mode of operation are recognized as part of the solution [1].

The smart city is expanding and has become a contemporary trend in all metropolitan areas, considering all elements in completing a solution connected to urban infrastructure. Bandung city, which is categorized as an urban area, is one of the metropolitan cities in Indonesia that has launched a smart city development. However, the deployment of smart city is a significant challenge in urban areas due to without appropriate management or diverting the direction of needs would cause the operational costs to soar [2]. Bandung city is the capital city of west Java province with an area of $167.31 \mathrm{~km}^{2}$ and an uneven topography; it consists of 30 districts in which 2.5 million people live. Bandung city is one of Indonesia's most populous cities with severe traffic jams, floods, and infrastructure maintenance. Based on the 2020-2024 national 
medium term development plan (RPJMN) of the republic of Indonesia, development policies and strategies in realizing a smart city can be done by utilizing reliable ICT in town services.

The low power wide area network (LPWAN)-based internet of things (IoT) is a new wireless trending technology to help people overcome global challenges. As for some of the IoT connectivity technology characteristics: low power and long-range, legacy wireless services that provide power: longrange (cellular technology: 3G/4G), low power and long-distance: short (ex: Bluetooth, Zig Bee, and WiFi), and low power wide area network (LPWAN), as illustrated in Figure 1. LPWAN-based IoT is a new wireless technology emerging to support the IoT paradigm with cheaper operation than traditional cellular network systems and better power efficiency [3]. Figure 1 shows that LPWAN is superior in cost, low power consumption, coverage, and geographic coverage penetration than cellular and short range device (SRD). However, LPWAN has low data throughput and delay.

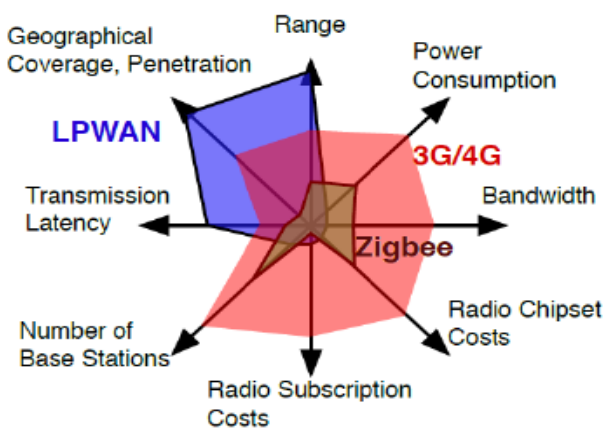

Figure 1. Wireless technology comparison [4]

LPWAN is divided into two licensing standards: the $3^{\text {rd }}$ generation partnership project (3GPP) standard (licensed spectrum) and non-3GPP standard (free license spectrum). Under the Regulation of the director-general of resources and equipment of post and information technology (Perdirjen SDPPI) no. 3 in 2019, the LPWAN frequency band is 920-923 MHz [5]. Narrow-band internet of things (NB-IoT), longrange wide area network (LoRaWAN), extended coverage-global system for mobile communications (ECGSM), long term evolution for machines (LTE-M), and Sigfox technologies apply frequency bands at 920$923 \mathrm{MHz}$, in contrast to random phase multiple access (RPMA) as shown in Table 1.

Table 1. LPWAN work frequency and spectrum standards for Asia [6]

\begin{tabular}{ccccccc}
\hline \multirow{2}{*}{ LPWAN } & \multicolumn{3}{c}{ 3GPP Rel. 13 Standard } & \multicolumn{3}{c}{ Non-3GPP Standard } \\
& NB-IoT & LTE-M & EC-GSM & LoRaWAN & Sigfox & RPMA \\
\hline $939.8 \mathrm{MHz}$ & $939.8 \mathrm{MHz}$ & $700-900 \mathrm{MHz}$ & $900 \mathrm{MHz}$ & $923 \mathrm{MHz}$ & $920.8 \mathrm{MHz}$ & $2.4 \mathrm{GHz}$ \\
\hline
\end{tabular}

The deployment of the LPWAN technologies is presented in Figure 2, with Figure 2(a) shows the NB-IoT and LTE-M deployment, Figure 2(b) presents the LoRaWAN deployment, Figure 2(c) illustrates Sigfox deployment and Figure 2(d) displays the RPMA deployment in Indonesia and around the world. LoRaWAN and Sigfox have the same frequency band and spectrum standards characteristics. However, NBIoT uses a licensed spectrum, and RPMA is a non-3GPP LPWAN standard that uses an operating frequency of $2.4 \mathrm{GHz}$.

Previous studies have explored the use of NB-IoT and LoRaWAN network planning for several use cases, namely AMI in dense-urban [7], urban, and sub-urban [8], [9]. However, minimal information was found regarding the deployment of NB-IoT and LoRaWAN networks for AMI, supporting multiple use cases simultaneously in one network, especially in urban scenarios. Therefore, this study aims to explore NB-IoT and LoRaWAN technologies as network connectivity for smart city services in Bandung city, representing the urban area and special economic zone in Indonesia.

In particular, a design of study comparative LPWAN: LoRaWAN, NB-IoT, and RPMA based on capacity and coverage planning analysis. LPWAN technology is chosen based on work standards, working frequency, and development in Indonesia. Network planning for LoRaWAN, NB-IoT, and RPMA smart city is based on capacity and coverage analysis. The capacity analysis is the number of data sessions conducted in 
an area within a certain period, while the coverage analysis is the percentage of the geographic area (Bandung city). Furthermore, the authors will analyze the technology comparison in the distribution of LPWAN in Bandung city.
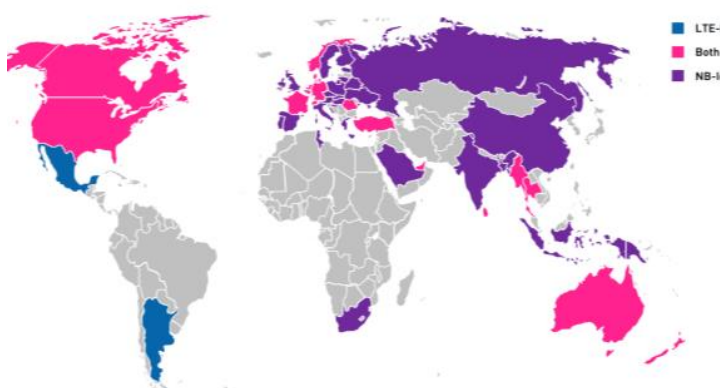

(a)

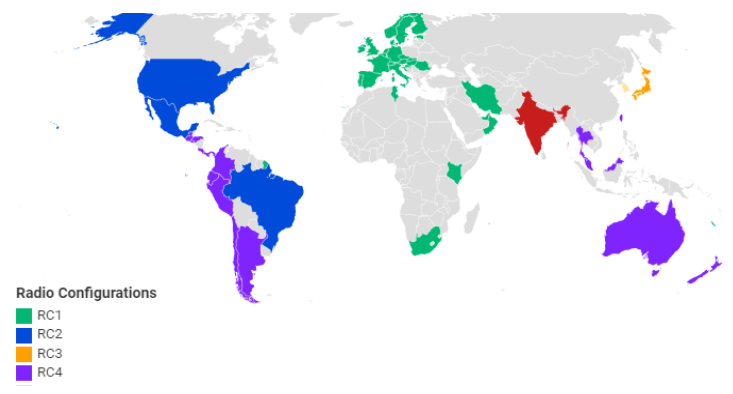

(c)

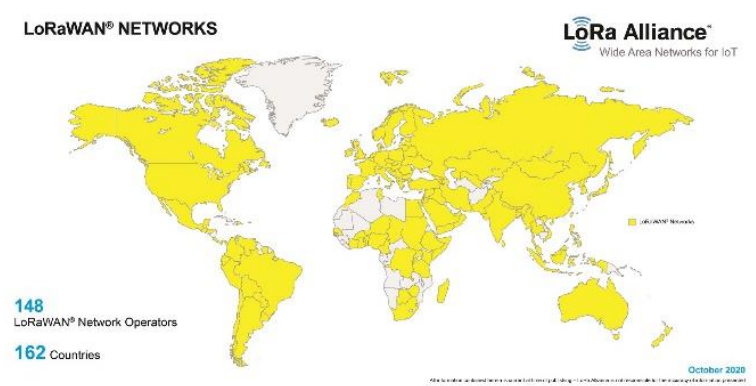

(b)

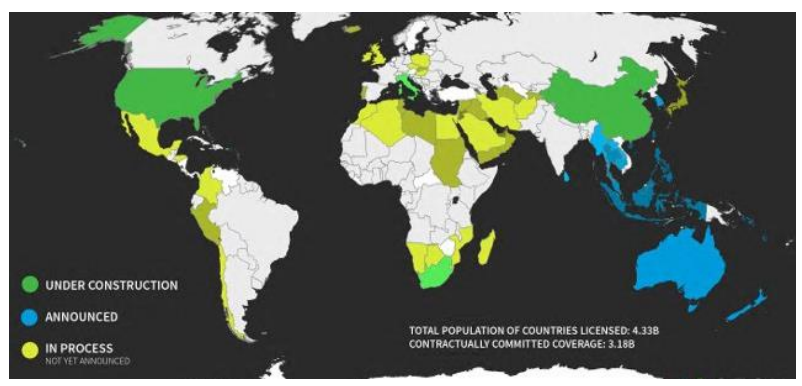

(d)

Figure 2. Deployment of LPWAN technologies: (a) NB-IoT and LTE-M, (b) LoRaWAN, (c) Sigfox, and (d) RPMA around the world

\section{RESEARCH METHOD}

Bandung city, which is the capital of West Java Province, has an area of $167.31 \mathrm{~km}^{2}$. Bandung city's population is projected to have 2.5 million in 2019. Hence, before LPWAN-based IoT connectivity services are implemented in Bandung city it is crucial to project the initial value in future market projections. It can be done by projecting the number of devices that need to be predicted in this study's implementation of an effective network with a ten-year range. The coverage and traffic requirements are the basic requirements in deploying LPWAN network planning.

\subsection{Capacity analysis}

\subsubsection{Subscriber demand forecasting}

Data/traffic requirements of LPWAN are another factor in the preparation or calculation of network deployment. This research was conducted from 2020 to 2030. Forecasting modeling the number of devices with the bass model [10], as in:

$$
N(t)=M \frac{1-e^{-(p+q) t}}{1+\frac{q}{p} e^{-(p+q) t}}
$$

$p>0$ is the innovation coefficient which is the probability of an initial purchase at the start of new network deployment, and $q \geq 0$ is the imitation coefficient which refers to the group size of future users.

\subsubsection{Traffic requirements projection}

Data/traffic requirements do not depend on the method of deploying the LPWAN. Data/traffic analysis in implementation is based on references [11]. One of the powerful features is the on-demand control requirements, in addition to scheduled controls or reads. Command-based requests require a network that listens and responds to on-demand commands promptly. So, bandwidth is not necessary since only latency is the most required. Therefore, IoT wireless connectivity must support two-way communication to ensure long 
service life and full functionality. Features and technical requirements of the smart city application in this study are shown in Table 2.

Table 2. Smart city technical requirements [12], [13]

\begin{tabular}{llcc}
\hline \multicolumn{1}{c}{ Use case } & \multicolumn{1}{c}{ Event trequency } & \multicolumn{2}{c}{ Payload } \\
& \multicolumn{1}{c}{ Utility-Meter } & Meter-Utility \\
\hline Meter reading on-demand & 25 per 1000 meter per day & 200 & 800 \\
Meter reading scheduled & 1 per meter per 6 hours & 12,800 & 12,800 \\
Meter system events & 4 per 1000 meter per month & & 2,224 \\
Outage restoration and management (ORM) & 1 per meter per event & & 200 \\
Real time pricing (RTP) & 60 per 1000 meter per day & 800 & 200 \\
Time of use (ToU) pricing & 60 per 1000 meter per day & 800 & 200 \\
Service switch operation & 50 per 1000 meter per day & 200 & 200 \\
\hline
\end{tabular}

\subsection{Coverage analysis}

Coverage planning analysis uses the link budget calculations. The results of coverage planning are anticipated to obtain the cell radius, which will then impact the coverage area, gateway or eNodeB configuration, and propagation models. In addition, link budget calculation obtains the maximum possible path loss estimation from the gains and losses of the antenna transmitter to the receiver, as formulated and illustrated in (2) and Figure 3 [14], [15].

$$
P_{R x}=P_{T x}-L_{T x}+G_{T x}-L_{P a t h}+G_{R x}-L_{R x}
$$

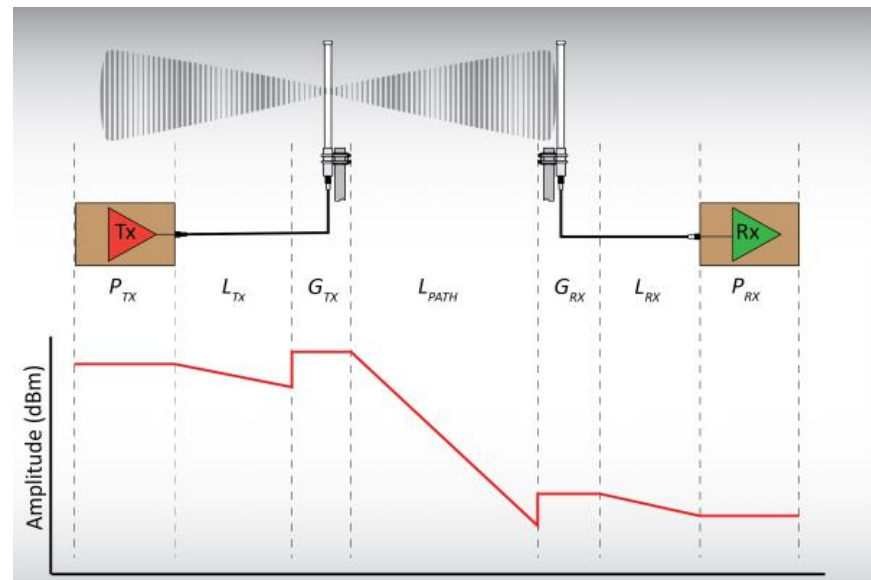

Figure 3. System's gain-loss profile for a link budget calculation [16]

Path loss calculations are carried out between the transmitter and receiver using the propagation model and other radio waves propagation calculations such as diffraction and image fading. The propagation model is a mathematical representation of the average loss in signal strength over a distance. Diffraction loss and shadow fading margin are added to averaging these losses to obtain precise path loss values. The path loss matrix is calculated for each transmitter, and the results are used in calculating the coverage. The calculation method may differ depending on the analysis performed, as shown in Table 3.

Table 3. Default propagation model [17]

\begin{tabular}{lll}
\hline \multicolumn{1}{c}{ Propagation model } & Erceg-Greenstein $(\mathrm{SUI})$ & \multicolumn{1}{c}{ Okumura-Hata } \\
\hline Frequency band & $1900-6000 \mathrm{MHz}$ & $150-1500 \mathrm{MHz}$ \\
Physical phenomena & $L\left(d, f, H_{T x}, H_{R x}\right)$ & \multicolumn{1}{c}{$L\left(d, f, H_{R x}\right)$} \\
Diffraction calculation method & Deygout $(1$ obstacle) & Deygout $(1$ obstacle) \\
Profile-based on & Digital Terrain Model & Digital Terrain Model \\
Profile extraction mode & Radial & Radial \\
Cell size & Macrocell \& Minicell & Macrocell \& Minicell \\
Receiver location & Street & Street \\
Use & RPMA & LoRaWAN \& NB-IoT \\
\hline
\end{tabular}

Indonesian J Elec Eng \& Comp Sci, Vol. 25, No. 1, January 2022: 425-439 
The Okumura-Hata formulas empirically describe the path loss as a function of frequency, transmitter-receiver distance, and antenna height for an urban area. This formula applies to flat, urban environments and a 1.5-meter LPWA antenna height. The path loss (Lu) is calculated in $\mathrm{dB}$ by using (3):

$$
L u=69.55+26.16 \log (f)-13.82 \log \left(h_{T x}\right)+\left(44.90-6.55 \log \left(h_{T x}\right)\right) \log d
$$

The Erceg-Greenstein propagation model is a statistical model of path loss from experimental data collected at $1.9 \mathrm{GHz}$ at 95 macrocells. This propagation model is very suitable for distances based on the frequency and height of the Gateway antenna. The line loss model applies antenna heights from 10 to $80 \mathrm{~m}$, gateway distances from 0.1 to $8 \mathrm{~km}$, and three terrain categories. The SUI model is divided into three types of terrain: A, B, and C, as shown in Table 4.

Table 4. SUI terrain types

\begin{tabular}{cccc}
\hline Model Parameter & Terrain A & Terrain B & Terrain C \\
\hline $\mathrm{A}$ & 4.6 & 4.0 & 3.6 \\
$\left.\mathrm{~b} \mathrm{(m} \mathrm{m}^{-1}\right)$ & 0.0075 & 0.0065 & 0.005 \\
$\mathrm{c}(\mathrm{m})$ & 12.6 & 17.1 & 20 \\
$\mathrm{X}$ & 10.8 & 10.8 & 20 \\
\hline
\end{tabular}

The Erceg-Greenstein propagation model (SUI) formula is derived from (4)-(6):

$$
P L=-7.366+26 \times \log _{10}(f)+10 \times a\left(h_{T x}\right) \times\left(1+\log _{10}(d)\right)-a\left(h_{R x}\right)
$$

$a\left(h_{R x}\right)$ is the correction for a receiving antenna height different from $1.5 \mathrm{~m}$. When the receiver antenna height is equal to $1.5 \mathrm{~m}$, a $a\left(h_{R x}\right)$ approaches $0 \mathrm{~dB}$ regardless of frequency:

$$
a\left(h_{R x}\right)=3.2\left(\log \left(11.75 h_{R x}\right)\right)^{2}-4.97
$$

the modeling scenario used in determining the LPWAN coverage area uses a hexagonal approach:

$$
S=\frac{3}{2} r^{2} \sqrt{3}
$$

each gateway or eNodeB of the LPWA network connectivity technology system (LoRaWAN, NB-IoT, and RPMA) has its range, which will affect the coverage of the area served. The area can be calculated from six hexagonal equilateral triangles.

\subsection{LPWAN comparative assessment}

A comparative study is the primary multi-attribute decision-making tool DEXi because of the tremendous dimensional optimization problem. It evaluates and contrasts two or more items or ideas side by side. Furthermore, a comparative study is a study that demonstrates the capacity to assess, compare, and contrast subjects or ideas with other issues or ideas. Comparative research indicates how two problems are similar or distinct topics. In addition, the inputs to the analysis are the expressed different model attributes and domain ranges.

\section{RESULTS AND DISCUSSION}

\subsection{Forecasting of IoT smart city penetration}

Forecasting IoT device share is an early-stage analysis in processing projection data. It is commonly utilized for obtaining the fundamental demands of device needs of LPWAN-based IoT connection that is performed on the projected data. Additionally, this forecasts the penetration depth for the IoT operator when implementing the LPWAN technologies inside the designated study region. This research, later, provides an estimated number for the IoT device share required for smart city deployment in Bandung city as a result of its findings.

\subsubsection{Forecasting of IoT smart city devices needed}

Bandung city is the capital of West Java. Bandung city is also known as a city for shopping and culinary tourism in the Republic of Indonesia. In 2019, there were 2,507,900 inhabitants. The total population of Bandung city in 2020 is 2,529,561 people. The number of connected IoT devices in the city must be prepared to determine LoRaWAN capabilities. Forecasting users of LPWAN-based IoT devices is done by 
using the geometric method. The number of IoT devices can be selected based on the traditional service users. The number of connected devices in Bandung City, as shown in Table 5. The number of LPWA-based IoT devices connected to smart city in Bandung city is 2,077,335. smart energy \& utilities are the most significant connected devices is $53 \%$, smart living is $0 \%$, smart mobility \& transportation is $43 \%$, and smart environment is $4 \%$, as illustrated in Figure 4.

Table 5. Bandung city's classifications type for smart city demographics projection area in 2020

\begin{tabular}{lcccc}
\multicolumn{1}{c}{ IoT smart city } & \multirow{2}{*}{ Growth rate } & \multicolumn{2}{c}{ Number of devices } & \multirow{2}{*}{ Density per sq. km } \\
\hline Smart electricity metering & $3.30 \%$ & $1,022,690$ & $11,675,333$ & $69,782.64$ \\
Smart water metering & $1.42 \%$ & 185,563 & 534,279 & $3,193.35$ \\
Smart fuel metering & $3.30 \%$ & 295 & 3,401 & 20.33 \\
Smart gas metering & $3.30 \%$ & 99 & 1,164 & 6.96 \\
Smart lighting & $3.30 \%$ & 305,749 & $3,490,541$ & $20,862.72$ \\
Smart energy \& utilities & $2.92 \%$ & $1,508,314$ & $13,099,109$ & $78,292.45$ \\
Smart parking & $8.35 \%$ & 6,987 & $2,860,993$ & $17,099.95$ \\
Smart traffic light & $8.35 \%$ & 828 & 339,524 & $2,029.31$ \\
Smart public transport & $8.35 \%$ & 18,206 & $7,454,327$ & $44,553.98$ \\
Smart mobility \& transportation & $8.35 \%$ & 26,018 & $10,652,608$ & $63,669.88$ \\
Smart waste management & $0.19 \%$ & 381,461 & 439,828 & $2,628.82$ \\
Smart air quality monitoring & $1.47 \%$ & 16,652 & 49,762 & 297.42 \\
Smart water quality monitoring & $1.42 \%$ & 309,302 & 890,549 & $5,322.75$ \\
Smart environment & $1.03 \%$ & 529,836 & $1,139,849$ & $6,812.80$ \\
Smart disaster warning \& alert systems & $1.03 \%$ & 13,167 & 22,257 & 133.03 \\
\multicolumn{1}{c}{ Total IoT device share } & & $2,077,335$ & $24,913,823$ & $148,908.15$ \\
\hline
\end{tabular}

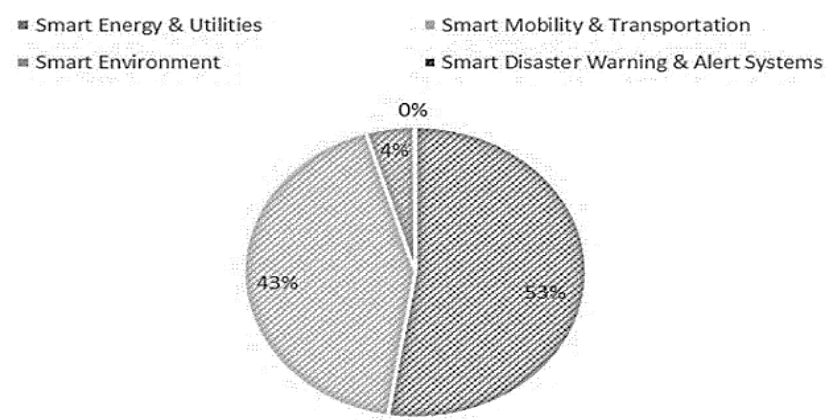

Figure 4. Percentage of smart city devices in 2030

\subsubsection{Forecasting of IoT smart city device share}

The number of devices connected to Bandung city is around 2,077,335. These devices form the basis for the projection of device shares. In order to meet the appropriate IoT network deployment needs, user/device projections need to be predicted. The projection of connected devices is analyzed using the bass model, as in (1). The same parameter values for $\mathrm{p}(0.00692)$ and $\mathrm{q}(0.04356)$, as done in a study to predict mobile broadband subscriptions in Thailand [10]. Previous research reports show a similar diffusion pattern for mobile broadband services in Indonesia and Thailand, strengthening comparative markets between the two countries. The saturation M (devices share) point occurs in the $73^{\text {rd }}$ year, as illustrated in Figure 5.

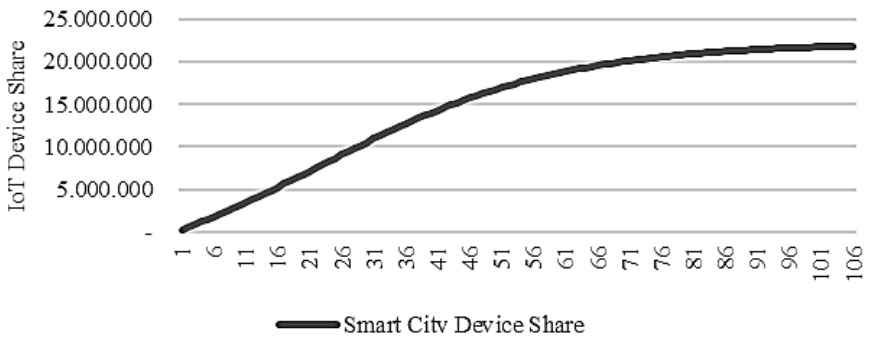

Figure 5. Saturation of IoT device smart city share 
Figure 5 shows the market capacity saturation value in considering the components of device needs in Bandung City. According to the average device battery life standard, the predicted values are attained for the ten-year perspective, with 2020 as the base year. The number of adoptions needs for IoT devices per district is carried out to obtain the demand growth for IoT devices in the first year (2021) of deployment until the $10^{\text {th }}$ year (2030) according to the average IoT battery capacity, as illustrated in Figure 6.

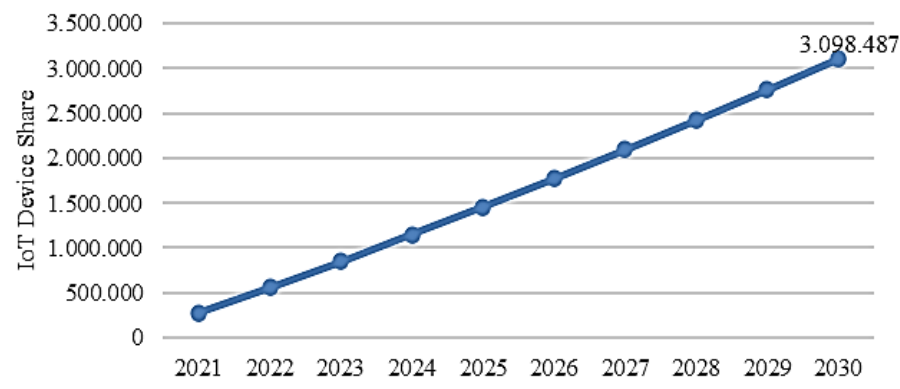

Figure 6. IoT smart city device share in Bandung city within the next ten years

\subsubsection{Data/traffic projection of IoT smart city needs}

IoT smart city of data/traffic needs projection is the basis for capacity planning in deploying LPWAN. Characteristic requirements based on forecasting the share of IoT devices refer to the mobile broadband market. As explained in the previous chapter, the data/traffic characteristics of IoT smart city refer to the use case, the number of messages each day, and the payload. For each district in Bandung city, the requirements for the number of packages needed per day are shown in Table 6.

Table 6. Total packet per day for Bandung city's IoT smart city

\begin{tabular}{lccc}
\hline \multicolumn{1}{c}{ Use case } & $\begin{array}{c}\text { Number of end device } \\
\text { (Unit) }\end{array}$ & $\begin{array}{c}\text { Number of packets per } \\
\text { day for one device }\end{array}$ & $\begin{array}{c}\text { Num. of required } \\
\text { packet (bps) }\end{array}$ \\
\hline Meter reading on-demand & 77,462 & 1 & 77,462 \\
Meter reading scheduled & $3,098,487$ & 4 & $12,393,946$ \\
Meter system events & $1,126,722$ & 0.042 & 46,984 \\
Outage restoration and management & $3,098,487$ & 1 & $3,098,487$ \\
Real time pricing & 185,909 & 1 & 185,909 \\
Time of use pricing & 185,909 & 1 & 185,909 \\
Service switch operation & 185,909 & 1 & 185,909 \\
Firmware updates & $6,196,973$ & 0.0027 & 16,978 \\
Direct load control & 185,909 & 1 & 185,909 \\
& \multicolumn{3}{c}{} \\
\hline
\end{tabular}

The final calculation of the number of devices is obtained in Table 6. The number of packets per day for one device, burstiness margin, and security margin is obtained based on assumptions. The number of packets required (bps) is the number of end devices shared and packets per day for one device. Thus, the number of packages needed per day is $16 \mathrm{Mbps}$.

\subsection{Capacity planning}

LoRaWAN, NB-IoT, and RPMA are the leading technologies in the IoT industry in recent days [18]. LoRaWAN is an un-3GPP technology led by Semtech. LoRaWAN's transmission bandwidth options are $125 \mathrm{kHz}, 250 \mathrm{kHz}$, and $500 \mathrm{kHz}$. According to regulations, Indonesia uses $125 \mathrm{kHz}$. $3 \mathrm{GPP}$ standardizes NB-IoT; NB-IoT's transmission bandwidth is $180 \mathrm{kHz}$ as 1 LTE Physical Resource Block (PRB). RPMA uses the $2.4 \mathrm{GHz}$ unlicensed universal band, which offers $80 \mathrm{MHz}$ bandwidth. RPMA uses the $2.4 \mathrm{GHz}$ unlicensed universal band, which offers $1 \mathrm{MHz}$ bandwidth.

\subsubsection{LoRaWAN capacity planning}

Networks are designed to be hassle-free and more effective. Therefore, the planned network capacity requirements must match the traffic requirements. LoRaWAN network capacity can be estimated from the input taken from time on air (ToA) packets or transmission times for data rate variations and distributions. The LoRaWAN package consists of several elements, as illustrated in Figure 7. 


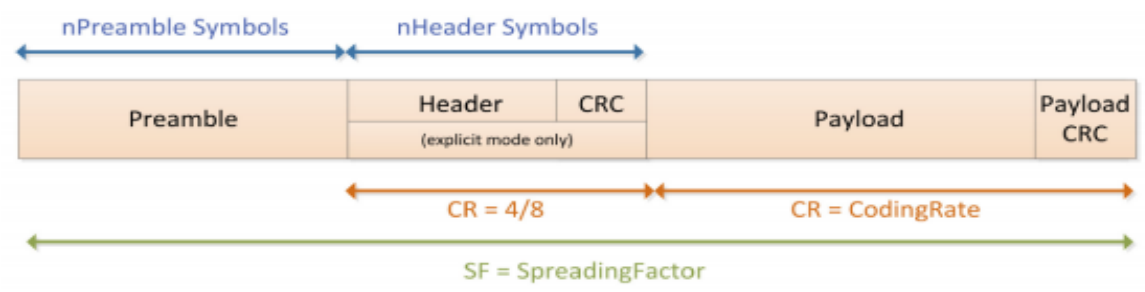

Figure 7. LoRaWAN modem packet

According to Semtech, the LoRaWAN frame duration, known as ToA or payload duration, consists of the actual opening and load of the packet, as described in (8)-(11):

$$
\begin{aligned}
& \text { ToA }=T_{\text {Preamble }}+T_{\text {Payload }} \\
& T_{\text {Preamble }}=T_{\text {sym }} \times\left(n_{\text {Preamble }}+4.25\right) \\
& T_{\text {Payload }}=\text { payloadSymbNb } \times T_{\text {Sym }} \\
& \text { payloadSymbNb }=8+\max \left(\operatorname{ceil}\left(\frac{8 P L-4 S F+28+16-20 H}{4(S F-2 D E)}\right)(C R+4), 0\right)
\end{aligned}
$$

in order to enable the various IoT application optimizations, LoRaWAN uses several necessary design parameters, namely bandwidth, Spreading factor (SF), and Coding rate (CR). This parameter allows the trade-off between data rate optimization, occupied bandwidth, interference, and increased link budget. The

\begin{tabular}{|c|c|c|c|c|c|c|c|c|}
\hline \multirow{2}{*}{$\begin{array}{l}\text { Spreading } \\
\text { factor (SF) }\end{array}$} & \multicolumn{4}{|c|}{ Coding rate $(\mathrm{CR})$} & \multicolumn{4}{|c|}{ Minimum capacity (Site) } \\
\hline & $\mathrm{CR}=1$ & $\mathrm{CR}=2$ & $\mathrm{CR}=3$ & $\mathrm{CR}=4$ & $\mathrm{CR}=1$ & $\mathrm{CR}=2$ & $\mathrm{CR}=3$ & $\mathrm{CR}=4$ \\
\hline SF8 & $7,803,468.21$ & $7,803,468.21$ & $7,988,165.68$ & $7,988,165.68$ & 3 & 3 & 3 & 3 \\
\hline SF10 & $2,205,882.35$ & $2,265,100.67$ & $2,265,100.67$ & $2,265,100.67$ & 8 & 8 & 8 & 8 \\
\hline SF11 & $1,074,840.76$ & $1,074,840.76$ & $1,102,941.18$ & $1,102,941.18$ & 16 & 16 & 15 & 15 \\
\hline SF12 & $566,275.17$ & $581,896.55$ & $581,896.55$ & $581,896.55$ & 29 & 29 & 29 & 29 \\
\hline
\end{tabular}
required capacity is obtained based on massive IoT devices' traffic characteristics and technical requirements, as shown in Table 7.

Table 7. Single gateway with eight-channel capacity (packet per day) MAX APP THP

SF and CR influence the demand needed for LoRaWAN gateways on capacity. The LoRaWAN gateway requirement is based on the SF range from SF7 up to SF12. The capacity planning gateway requirements indicate that SF12 has more important gateway requirements than SF11, SF10, SF9, SF8, and $\mathrm{SF} 7$, resulting in 29 sites for Bandung city.

\subsubsection{NB-IoT capacity planning}

The required capacity is based on massive IoT devices' traffic characteristics and technical requirements. The scenarios can be developed based on the connected density, as shown in Table 8 . The number of gateways required in the capacity analysis is strongly influenced by households' density per $\mathrm{km}^{2}$ and devices. The analysis is based on 3GPP Rel.13 TR 45.820 V.2.1.0 [19], which supports 45,000 in every three sectoral cells. Therefore, the total gateway requirement in Bandung city is 23 sites.

Table 8 . Device density assumption per cell (London model)

\begin{tabular}{lr}
\hline \multicolumn{1}{c}{ Case } & Urban \\
\hline Household density per km ${ }^{2}$ & 45,000 \\
Inter-site distance (ISD) (km) & 53 \\
Number of devices within a household & 40 \\
Number of devices within a cell site & 54,280 \\
Number of devices (Unit) & $3,098,487$ \\
Number of cell needed (Cell) & 69 \\
Minimum capacity (Site) & 23 \\
\hline
\end{tabular}

Indonesian J Elec Eng \& Comp Sci, Vol. 25, No. 1, January 2022: 425-439 


\subsubsection{RPMA capacity planning}

The total application throughput calculates the RPMA capacity that the network can support. Therefore, the term total application throughput can be described as the acceptance rate of data on one part of the network's gateway infrastructure, as stated in Table 9. The values of the RPMA parameter formulate the RPMA capacity. Capacity planning is needed in obtaining the technical requirements for massive IoT device implementation. The RPMA capacity represents 3\% of capacity planning (30/1000). Based on this, the required RPMA gateway is eight sites.

Table 9. Application throughput parameter of RPMA

\begin{tabular}{llc}
\hline & Parameter & Value \\
\hline PHY calculation & (1) link data rate & 960 \\
& (2) Number of Simultaneous Links & 1,200 \\
& (3) Sectorization links & 1 \\
& (4) PHY throughput & $1,152,000$ \\
MAC calculation & (5) Repetition de-rate & 1 \\
& (6) Other cell interference de-rate & 1.4 \\
& (7) Half-duplex de-rate & 2 \\
& (8) Mac protocol de-rate & 3 \\
Total application throughput (bps)/MHz $(4 /(5 * 6 * 7 * 8 * 9))$ & 68,571 \\
Total packet per day * 3\% (bps) & $491,324.82$ \\
Minimum capacity (Sites) & 8 \\
\hline
\end{tabular}

\subsection{Coverage planning}

\subsubsection{LoRaWAN coverage planning}

Several parameters must be determined based on coverage planning, as shown in Table 10. First, the received signal level must be identified; this provides the closest to the extreme level of coverage. Therefore, in (12) and (13) are utilized to know the maximum propagation attenuation to avoid interference. After calculating the link budget, a coverage area analysis is needed to determine the LoRaWAN coverage capability based on area characteristics (urban). LoRaWAN coverage analysis used the Okumura-Hata propagation model based on (2) to obtain the LoRaWAN cell area. Coverage analysis was analyzed using Okumura-Hata propagation, as shown in Table 11. Due to the widest spreading, SF12 is used. Therefore, the number of gateways required is only one.

$$
\begin{aligned}
& R S S I=-174+10 \log (B W)+N F+S N R \\
& M A P L=E i R P-R S S I
\end{aligned}
$$

Table 10. Configuration of LoRaWAN parameters [14]

\begin{tabular}{ccccc}
\hline \multicolumn{2}{c}{$\begin{array}{c}\text { MCI Regulation of the } \\
\text { Republic of Indonesia 1/2019 }\end{array}$} & \multicolumn{2}{c}{ LoRaWAN Parameter } & \multicolumn{2}{c}{ Height of Transmitter and Receiver } \\
\hline Frequency band & $920-923$ & Bandwidth (Hz) & 125,000 & Height of Antenna for Urban Area (m) \\
(MHz) & Max Antenna Power (dBm) & 23 & Height of Receiver (m) \\
& Gain Transmitter (dBi) & 5 & \\
& Gain Receiver (dBi) & 2 & \\
\hline
\end{tabular}

\begin{tabular}{|c|c|c|c|c|c|c|c|c|c|c|}
\hline SF & SNR & $\mathrm{NF}$ & Sensitivity & EiRP & MAPL & $\mathrm{a}(\mathrm{hR})$ & $\mathrm{D}(\mathrm{km})$ & Cell area $\left(\mathrm{km}^{2}\right)$ & Area $\left(\mathrm{km}^{2}\right)$ & $\begin{array}{c}\text { Number of } \\
\text { gateway (Site) }\end{array}$ \\
\hline SF7 & -7.5 & 6 & -125 & 21 & 150 & 0.01687 & 4.7517 & 58.661 & 167.31 & 3 \\
\hline SF8 & -10 & 6 & -127 & 21 & 153 & 0.01687 & 5.5953 & 81.338 & 167.31 & 3 \\
\hline SF9 & -12.5 & 6 & -130 & 21 & 155 & 0.01687 & 6.5886 & 112.78 & 167.31 & 2 \\
\hline SF10 & -15 & 6 & -132 & 21 & 158 & 0.01687 & 7.7583 & 156.38 & 167.31 & 2 \\
\hline SF11 & -17.5 & 6 & -135 & 21 & 160 & 0.01687 & 9.1356 & 216.83 & 167.31 & 1 \\
\hline SF12 & -20 & 6 & -137 & 21 & 163 & 0.01687 & 10.757 & 300.66 & 167.31 & 1 \\
\hline SF7 & -7.5 & 6 & -125 & 21 & 150 & 0.01687 & 4.7517 & 58.661 & 167.31 & 3 \\
\hline
\end{tabular}

Table 11. LoRaWAN, link budget results, based on spreading factor (SF)

\subsubsection{NB-IoT coverage planning}

NB-IoT uses three-sectoral in eNodeB cells, as illustrated in Figure 8. Using the three-sectoral cell is to increases the range and capacity. ISD value is used to determine the area of the three-sectoral cell. ISD is a measure in classifying eNodeB density in cellular networks as stated in 3GPP TR45.820 [20]. The maximum allowed path loss (MAPL) calculation is based on the difference between the measured power level in the 
transmitting, receiving transmitting, and receiving antennas [7]. Cell power calculations follow 3GPP standards and MAPL. Several parameters are needed to predict coverage planning, as shown in Table 12.

The Okumura-Hata propagation model is used to describe the cell area's ability to be covered [21]. The Okumura-Hata propagation model analysis for NB-IoT technology is analyzed based on the classification of the type of area, as shown in Table 13. The configuration of parameters for each characteristic of an area indicates different coverage capabilities. For example, one site is one of the required numbers of eNodeB (NB-IoT) network designs for Smart City.

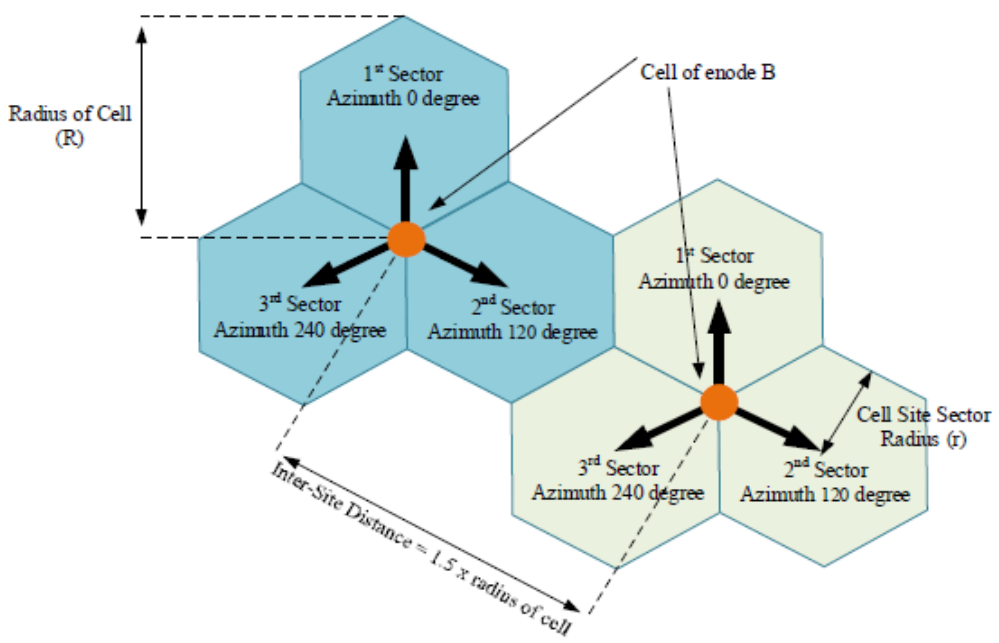

Figure 8. Illustration of three-sectoral cells in NB-IoT [20]

Table 12. NB-IoT link budget calculation

\begin{tabular}{|c|c|c|}
\hline Parameter & PUSCH & PDSCH \\
\hline Frequency Based on Stand-alone (MHz) & 900 & 900 \\
\hline Frequency Based on Operation (MHz) & 940 & 940 \\
\hline Bandwidth Channel (Stand-alone) (kHz) & 200 & 200 \\
\hline \multicolumn{3}{|l|}{ TRANSMITTER } \\
\hline Max Tx Power (dBm) & 23 & 43 \\
\hline (a) Actual Tx Power $(\mathrm{dBm})$ & 23 & 43 \\
\hline Gain Antenna Tx $(\mathrm{dBi})$ & 4 & 17 \\
\hline Height of Antenna's Tx [Urban] (m) & 1.5 & 30 \\
\hline \multicolumn{3}{|l|}{ RECEIVER } \\
\hline (b)Thermal Noise Density $(\mathrm{dBm} / \mathrm{Hz})$ & -174 & -174 \\
\hline (c) Receiver Noise Figure (dB) & 3 & 5 \\
\hline (d) Interference Margin (dB) & 0 & 0 \\
\hline (e) Occupied Channel Bandwidth $(\mathrm{Hz})$ & 15,000 & 180,000 \\
\hline (f) Effective Noise Power $=(\mathrm{b})+(\mathrm{c})+(\mathrm{d})+10 \log (\mathrm{e})(\mathrm{dBm})$ & -129 & -116 \\
\hline (g) Required SINR (dB) & -12 & -5 \\
\hline (h) Receiver Sensitivity = (f) + (g) (dBm) & -141 & -121 \\
\hline (i) Rx Processing Gain (dBi) & 0 & 0 \\
\hline (j) MAPL $=(a)-(h)+(i)(d B)$ & 164 & 164 \\
\hline
\end{tabular}

Table 13. NB-IoT eNodeB requirement based on coverage analysis

\begin{tabular}{llc}
\hline \multicolumn{1}{c}{ Okumura-Hata } & Power $(\mathrm{kW})$ \\
\hline Link budget/MAPL $(\mathrm{dBm})$ & & 164 \\
Gateway & $\mathrm{hT}(\mathrm{m})$ & 30 \\
Height of end device & $\mathrm{hR}(\mathrm{m})$ & 35 \\
Frequency & $\mathrm{Frq}(\mathrm{MHz})$ & 940 \\
Height of correction factor & $\mathrm{a}(\mathrm{hR})$ & 0.0176 \\
Range & $\mathrm{R}(\mathrm{km})$ & 11.6 \\
Inter-site distance (ISD) & & 17.5 \\
Cell site sector radius (km) & & 5.82 \\
Cell area (km $\left.{ }^{2}\right)$ & 352.30 \\
Area (km $\left.{ }^{2}\right)$ & 167.31 \\
Number of cell & 1 \\
Number of eNodeB (Trisectoral) & 1 \\
\hline
\end{tabular}

Indonesian J Elec Eng \& Comp Sci, Vol. 25, No. 1, January 2022: 425-439 


\subsubsection{RPMA coverage planning}

Table 14 shows several parameters that need to be determined based on coverage planning. First, the received signal level must be identified; this provides the closest to the outer level of coverage. Second, before knowing the coverage area capability of the RPMA, it is necessary to know the maximum propagation attenuation to avoid interference. Third, the RPMA frequency uses $2.4 \mathrm{MHz}$, so the RPMA coverage analysis is analyzed based on the Erceg-Greenstein (SUI) propagation model to explain the cell area. The ErcegGreenstein (SUI) Terrain A propagation model for RPMA in Bandung city is shown in Table 15 [23].

The configuration parameters for each area's characteristic within a single area coverage capability related to the Erceg-Greenstein propagation model (SUI) show that the coverage capability is not much different in each region type classification. This is because the terrain of an area influences the ErcegGreenstein (SUI) propagation model. Based on the coverage analysis, it was found that the number of gateways needed in planning the RPMA-based IoT network design for smart city services requires one site.

Table 14. RPMA link budget calculation [22]

\begin{tabular}{|c|c|c|c|c|c|}
\hline Parameter & & Transmitter & & Receiver & \\
\hline $\begin{array}{l}\text { Frequency/Frq Down } \\
(\mathrm{MHz})\end{array}$ & 2.400 & $\begin{array}{l}\text { (a) Max Antenna Power/Tx } \\
\text { Power }(\mathrm{dBm})\end{array}$ & 36 & (c) Rx Gain (dBi) & 6 \\
\hline $\begin{array}{l}\text { Frequency/Frq Uplink } \\
(\mathrm{MHz})\end{array}$ & 2.483 & $\begin{array}{l}\text { (b) Antenna Gain/Tx Gain } \\
\text { (dBi) }\end{array}$ & 9 & Height of End Device/hR (m) & 1.5 \\
\hline \multirow[t]{4}{*}{ Bandwidth (MHz) } & 1 & $\begin{array}{l}\text { Height of Gateway/hT } \\
\text { [Urban] }(\mathrm{m})\end{array}$ & 30 & RF Sensitivity at radio module $(\mathrm{dBm})$ & $\begin{array}{c}- \\
135\end{array}$ \\
\hline & & & & Losses & 5 \\
\hline & & & & $\operatorname{EiRP}=(a)+(b)+(c)$ & 21 \\
\hline & & & & $\begin{array}{l}\text { Maximum Allowable Path Loss }(\mathrm{dB})= \\
\text { (a) }- \text { RF Sensitivity }+ \text { (c) }\end{array}$ & 177 \\
\hline
\end{tabular}

Table 15. RPMA's gateway requirement based on coverage analysis

\begin{tabular}{lc}
\hline \multicolumn{1}{c}{ Erceg-Greenstein (SUI) } & Urban \\
\hline Height of Transmitter Correction Factor & 4.795 \\
Height of Receiver Correction Factor & -1.34934 \\
Radius Cell $(\mathrm{km})$ & 9.637536 \\
Cell Area $\left(\mathrm{km}^{2}\right)$ & 241.3148 \\
Area $\left(\mathrm{km}^{2}\right)$ & 167.31 \\
Number of Gateways (Sites) & 1 \\
\hline
\end{tabular}

\subsection{Gateway requirements}

The number of gateways needed to meet the needs of IoT for smart city in Bandung city is obtained from calculating the capacity and coverage planning analysis. The LoRaWAN working specifications use SF7 to SF12 [24]. Therefore, the gateway requirements are based on capacity and coverage planning analysis, calculated using (14) [25].

$$
\text { GatewayReq = Max\{No.of Gateways (coverage), No.of Gateways (capacity) }\}
$$

Based on the capacity analysis calculation in Tables 8, 9, and 10. It is obtained that the minimum gateway requirements are 29 for LoRaWAN, 23 for NB-IoT, and eight for RPMA. While in coverage analysis calculation as shown in Tables 12,14 , and 16, the obtained result shows that only one gateway is required for all LPWAN technologies: RPMA $=$ NB-IoT $=$ LoRaWAN. By referring to (14), the number of gateways required to serve Bandung city is 29 for LoRaWAN, 23 for NB-IoT, and eight for RPMA. Therefore, the LoRaWAN technology requires a much larger gateway than NB-IoT and RPMA technologies, simplified into RPMA < NB-IoT < LoRaWAN as illustrated in Table 16.

Table 16. Comparison of LoRaWAN, NB-IoT, and RPMA's gateway requirements

\begin{tabular}{lclccc}
\hline Technology & Number of devices & Area $\left(\mathrm{km}^{2}\right)$ & No. of Gateway (capacity) & No. of Gateway (coverage) & Gateways requirements \\
\hline LoRaWAN & $3,098,487$ & 167.31 & 29 & 1 & 29 \\
NB-IoT & $3,098,487$ & 167.31 & 23 & 1 & 23 \\
RPMA & $3,098,487$ & 167.31 & 8 & 1 & 8 \\
\hline
\end{tabular}

\subsection{LoRaWAN, NB-IoT, and RPMA signal distribution prediction results}

From calculating the capacity and coverage planning analysis, the number of gateways needed is acquired to meet the needs of smart city network deployment in Bandung city. Particularly for LoRaWAN 
technology since its gateway requirements are analyzed based on SF12. The LoRaWAN, NB-IoT, and RPMA gateway are positioned [26].

\subsubsection{The best signal level prediction results}

Based on the prediction results, as illustrated in Figure 9, the steadiest LoRaWAN signal levels from $-140 \mathrm{dBm}$ to $-65 \mathrm{dBm}$ with a mean value of $-84.38 \mathrm{~dB}$. Therefore, the best LoRaWAN signal levels are -115 $\mathrm{dBm}$ to $-110 \mathrm{dBm}$ with a $-15.94 \%$ distribution, as shown in Figure 9(a). On the other hand, the obtained NBIoT signal levels are from $-105 \mathrm{dBm}$ to $-100 \mathrm{dBm}$, with a mean value of $-76.08 \mathrm{dBm}$. Hence, the most satisfactory NB-IoT signal levels are $-95 \mathrm{dBm}$ to $-90 \mathrm{dBm}$ with a $21.42 \%$ distribution, illustrated in Figure 9(b). Meanwhile, in RPMA, the attained signal levels are from $-140 \mathrm{dBm}$ to $-65 \mathrm{dBm}$, with a mean value of $70.21 \mathrm{dBm}$. Thus, the optimum RPMA signal levels are $-110 \mathrm{dBm}$ to $-105 \mathrm{dBm}$ with a $17.33 \%$ distribution, as shown in Figure 9(c).

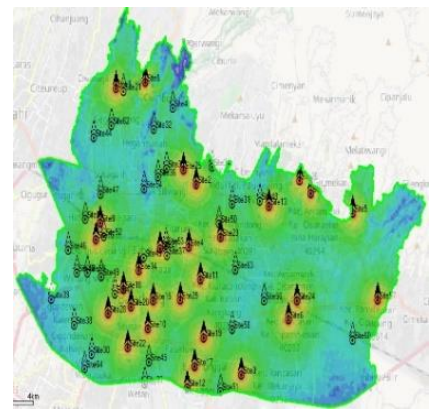

(a)

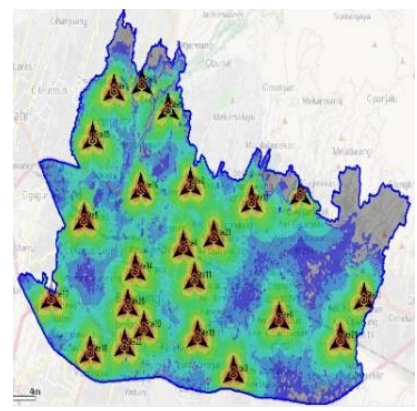

(b)

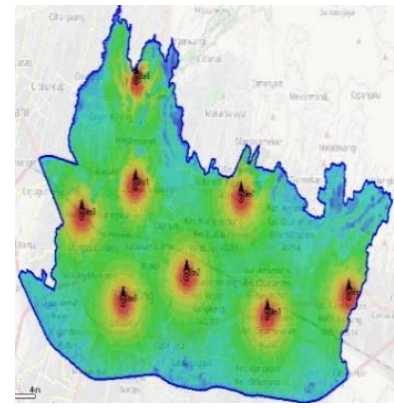

(c)

Figure 9. The optimum signal level distribution in Bandung city according to: (a) LoRaWAN, (b) NB-IoT, and (c) RPMA technologies

The prediction simulation results show that the best average signal level based on the capacity planning analysis in Bandung city is NB-IoT, followed by RPMA and LoRaWAN. Based on the prediction distribution from these three technologies. It can be concluded that LoRaWAN $<$ NB-IoT $<$ RPMA, as shown in Table 17.

Table 17. Percentage of LoRaWAN, NB-IoT, and RPMA's optimum signal level

\begin{tabular}{cccc}
\hline Best signal level $(\mathrm{dBm})$ & \multicolumn{3}{c}{ Percentage } \\
& LoRaWAN & NB-IoT & RPMA \\
\hline$[-140 ;-135]$ & $0.29 \%$ & - & $0.24 \%$ \\
{$[-135 ;-130]$} & $0.56 \%$ & - & $0.84 \%$ \\
{$[-130 ;-125]$} & $3.13 \%$ & - & $2.07 \%$ \\
{$[-125 ;-120]$} & $6.95 \%$ & - & $6.27 \%$ \\
{$[-120 ;-115]$} & $12.58 \%$ & - & $11.49 \%$ \\
{$[-115 ;-110]$} & $17.08 \%$ & - & $13.59 \%$ \\
{$[-110 ;-105]$} & $16.46 \%$ & - & $17.33 \%$ \\
{$[-105 ;-100]$} & $14.32 \%$ & $10.17 \%$ & $16.32 \%$ \\
{$[-100 ;-95]$} & $11.17 \%$ & $17.49 \%$ & $10.8 \%$ \\
{$[-95 ;-90]$} & $7.83 \%$ & $21.42 \%$ & $7.26 \%$ \\
{$[-90 ;-85]$} & $4.61 \%$ & $18.77 \%$ & $4.89 \%$ \\
{$[-85 ;-80]$} & $2.48 \%$ & $13.34 \%$ & $3.24 \%$ \\
{$[-80 ;-75]$} & $1.28 \%$ & $8.9 \%$ & $2.08 \%$ \\
{$[-75 ;-70]$} & $0.69 \%$ & $5.72 \%$ & $1.37 \%$ \\
{$[-70 ;-65]$} & $0.59 \%$ & $4.18 \%$ & $2.2 \%$ \\
\hline
\end{tabular}

\subsubsection{Overlapping zones prediction results}

Figure 10 shows the overlapping zones on the distribution of three LPWAN technologies, with Figure 10(a) presents the LoRaWAN overlapping zones, Figure 10(b) for NB-IoT overlapping zones, and Figure 10(c) for RPMA servers from one server to five servers across the whole Bandung city. The simulation prediction results show that the average number of overlapping zones on the server based on the capacity analysis on LoRaWAN is 1.39 servers, NB-IoT is 1.44 servers, and RPMA is 1.22 servers. Thus, the adequate number of overlapping zones can be concluded into RPMA $<$ LoRaWAN $<$ NB-IoT. 


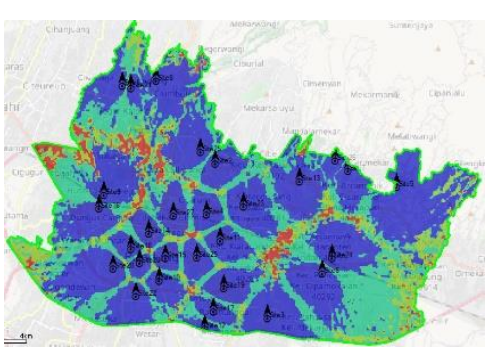

(a)

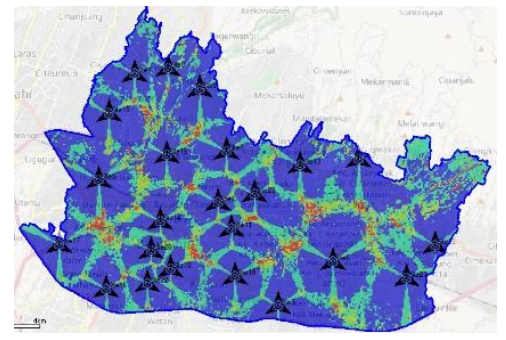

(b)

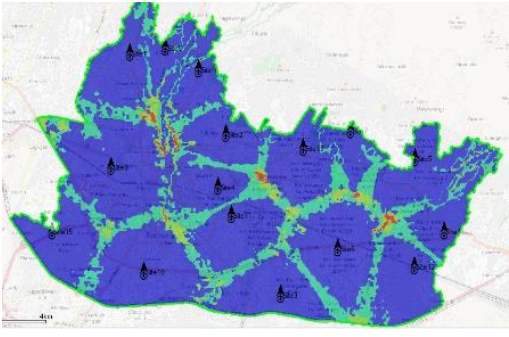

(c)

Figure 10. Three LPWAN technologies: (a) LoRaWAN, (b) NB-IoT, and (c) RPMA's overlapping zones distribution in Bandung city

The prediction simulation results show that the overlapping zones are based on capacity planning analysis. Therefore, it can be concluded that the optimum number of overlapping zones between LoRaWAN, NB-IoT, and RPMA servers is LoRaWAN $<$ NB-IoT<RPMA, as shown in Table 18.

Table 18. Percentage of the LoRaWAN, NB-IoT, and RPMA's overlapping zones

\begin{tabular}{cccc}
\hline $\begin{array}{c}\text { Overlapping zones } \\
\text { (Servers) }\end{array}$ & LoRaWAN & Percentage \\
\hline$[1-2]$ & $68.1 \%$ & $67.9 \%$ & $79.9 \%$ \\
{$[2-3]$} & $22.6 \%$ & $23.5 \%$ & $17.8 \%$ \\
{$[3-4]$} & $6.6 \%$ & $6.4 \%$ & $2 \%$ \\
{$[4-5]$} & $2.7 \%$ & $2.2 \%$ & $0.2 \%$ \\
\hline
\end{tabular}

\subsection{Summary of LoRaWAN, NB-IoT, and RPMA}

The summary for determining the criteria for the technical aspects of each LPWAN technology is shown in Table 19. The gateway requirement for LoRaWAN is 29 sites, while NB-IoT requires 23 sites, and RPMA demands only 8 sites. Overall, the RPMA technology network implementation looks superior to LoRaWAN and NB-IoT for smart city in the Bandung city area. This is because RPMA necessitates the smallest number of sites for smart city deployment. Therefore, it can be inferred that RPMA, aside from being superior to the other two LPWAN technologies, also provides more optimal connectivity.

Table 19. Summary of LPWAN technologies for IoT smart city in Bandung city

\begin{tabular}{lccc}
\hline Technical Evaluation Criteria & LoRaWAN & NB-IoT & RPMA \\
\hline Gateway Requirement & 29 sites & 23 sites & 8 sites \\
Traffic/Data Projection & $16,377,494$ & $16,377,494$ & $16,377,494$ \\
The Best Signal Level & $-84.38 \mathrm{dBm}$ & $-76.08 \mathrm{dBm}$ & $-70.21 \mathrm{dBm}$ \\
Overlapping Zones & 1.39 servers & 1.44 servers & 1.22 servers \\
\hline
\end{tabular}

\section{CONCLUSION}

This study contributed to comparing LPWAN-based IoT for Smart city in Bandung city. The comparison of LPWAN is aimed to determine the needs and selection of technology based on coverage and capacity network. The three LPWA technologies were selected based on the LPWAN coverage map, working frequency, and spectrum standards. Based on the analysis of the bass model, there were 3,098,487 devices shared in 2030. The analysis of network planning for smart city applications in Bandung city consisted of smart environment (4\%), smart energy \& utilities (53\%), smart mobility \& transportation (43\%), and smart Living $(0 \%)$.

Thus, the total number of packages required per day for smart city is $16,377,494 \mathrm{bps}$. The gateways required to serve Bandung city were 29 for LoRaWAN, 23 for NB-IoT, and eight for RPMA. The LoRaWAN technology requires a much larger gateway than NB-IoT and RPMA. Based on the simulation analysis results, the mean values representing the optimum signal level for LoRaWAN was $-84.38 \mathrm{dBm}$, NBIoT was $-76.08 \mathrm{dBm}$, and RPMA was $-70.21 \mathrm{dBm}$. Furthermore, 1.39, 1.44, and 1.22 servers were the average overlapping LoRaWAN, NB-IoT, and RPMA zones correspondingly.

LPWAN-based IoT results for smart city implementations showed that RPMA was preferred in gateway requirements, best signal levels, and overlapping zones than the other two technologies: LoRaWAN and NB-IoT. Simultaneously, NB-IoT, comprised of cell site and cell area, was superior in coverage 
capabilities. Since this research was focused on network connectivity, further study can be carried out, namely, cost-benefit analysis, sensors, and platforms aspects of getting an actual picture of smart city concepts in Bandung city

\section{ACKNOWLEDGEMENTS}

The authors greatly appreciated the Telecommunication Engineering and Postgraduate Program in regulation \& management of telecommunication, School of Electrical Engineering, Telkom University, and colleagues, Rizki Raharjo and Muhammad Adam Nugraha, for the support contributed to completing this study. In addition, the authors would also like to thank Mr. Adnan Batara, a country manager from the Ingenu IoT Indonesia Corporation on the assistance provided in this research.

\section{REFERENCES}

[1] M. Weber, D. Lučić, and I. Lovrek, "Internet of Things context of the smart city," In 2017 International Conference on Smart Systems and Technologies (SST), 2017, pp. 187-193, doi: 10.1109/SST.2017.8188693.

[2[ S. Fernandez, Dorota, and Danuta Stawasz, "The Concept Of Smart City In The Theory And Practice Of Urban Development Management," Romanian Journal of Regional Science, vol. 10, no. 1, pp. 86-99, 2016.

[3] B. S. Chaudari, M. Zennaro, and S. Borkar, "LPWAN Technologies: Emerging Application Characteristics, Requirements, and Design Considerations," Future Internet, vol. 12, no. 3, 2020, doi: 10.3390/fi12030046.

[4] D. M. Hernandez, G. Peralta, L. Manero, R. Gomez, J. Bilbao, and C. Zubia, "Energy and coverage study of LPWAN schemes for Industry 4.0," In Proc. 2017 IEEE Int. Work. Electron. Control. Meas. Signals their Appl. to Mechatronics, ECMSM 2017, 2017, doi: 10.1109/ECMSM.2017.7945893.

[5] Kominfo, "SDPPI Director General Regulation No. 3 Year 2019." p. 38, 2019. [Online] Avaliable: https://web.kominfo.go.id/sites/default/files/users/3997/PERDIRJEN\%20SDPPI\%20NO\%203\%20TAHUN\%202019\%20LPWA. pdf.

[6] D. C. Rufas, A. G. Pons, and J. Carrabina, "The Regulation of Unlicensed Sub-GHz bands: Are Stronger Restrictions Required for LPWAN-based IoT Success?," 2018.

[7] E. S. Santoso, A. Hidayati, M. Suryanegara, and M. I. Nashiruddin, "NB-IoT Network Planning for Smart Metering Services in Jakarta, Depok, Tangerang, and Bekasi," In 2019 16th International Conference on Quality in Research (QIR): International Symposium on Electrical and Computer Engineering, 2019, pp. 1-6, doi: 10.1109/QIR.2019.8898262.

[8] A. Hidayati, M. Reza, N. M. Adriansyah, and M. I. Nashiruddin, "Techno-Economic Analysis of Narrowband IoT (NB-IoT) Deployment for Smart Metering," In 2019 Asia Pacific Conference on Research in Industrial and Systems Engineering (APCoRISE), 2019, pp. 1-6, doi: 10.1109/APCoRISE46197.2019.9318920.

[9] M. I. Nashiruddin and A. Hidayati, "Techno-economic analysis of LoRa WAN deployment for typical massive IoT applications in Urban and suburban areas," Test Eng. Manag., vol. 83, pp. 8166-8176, 2020.

[10] H. Sudtasan and T. Mitomo, "Comparison of Diffusion Models for Forecasting the Growth of Broadband Markets in Thailand," In 14th ITS Asia-Pacific Regional Conference, Kyoto 2017, 2017.

[11] P. White, "Network planning," Public Transp., pp. 131-157, 2018, doi: 10.4324/9781315675770-7.

[12] M. T. Baja Sihotang, M. I. Nashiruddin, and M. A. Murti, "LoRaWAN Internet of Things Network Planning for Smart City in Bandung Areas," In 2020 11th IEEE Annual Information Technology, Electronics and Mobile Communication Conference (IEMCON), 2020, pp. 0582-0588, doi: 10.1109/IEMCON51383.2020.9284854.

[13] M. T. B. Sihotang, M. I. Nashiruddin, and M. A. Murti, "Planning for NB-IoT Smart City Network Deployment in Bandung Areas," In 2021 IEEE 11th Annual Computing and Communication Workshop and Conference (CCWC), 2021, pp. 1471-1477, doi: 10.1109/ccwc51732.2021.9376149.

[14] S. Patel, R. Y. Uday Kumar, and B. Prasanna Kumar, "Role of smart meters in smart city development in India," In 1st IEEE Int. Conf. Power Electron. Intell. Control Energy Syst. ICPEICES 2016, pp. 1-5, 2017, doi: 10.1109/ICPEICES.2016.7853363.

[15] M. Burhan, R. A. Rehman, B. Khan, and B. S. Kim, "IoT elements, layered architectures and security issues: A comprehensive survey," Sensors (Switzerland), vol. 18, no. 9, 2018, doi: 10.3390/s18092796.

[16] C. Scientific, "The Link Budget and Fade Margin," 2016. [Online]. Avaliable: https://s.campbellsci.com/documents/us/technicalpapers/link-budget.pdf

[17] F. Atoll, "Technical Reference Guide for Radio Networks," 1997. [Online]. Avaliable: https://www.forsk.com/sites/default/ files/atoll_34_sept2018-light_0.pdf

[18] S. C. Gaddam and M. K. Rai, "A Comparative Study on Various LPWAN and Cellular Communication Technologies for IoT Based Smart Applications," In 2018 International Conference on Emerging Trends and Innovations In Engineering And Technological Research (ICETIETR), 2018, pp. 1-8, doi: 10.1109/ICETIETR.2018.8529060.

[19] E. Tr, "Digital cellular telecommunications system ( Phase 2+); Background for Radio Frequency ( RF ) requirements," 2016. https://www.zmailer.org/m/ham/GSM/GSM-05.50.pdf

[20] A. Landström, H. Jonsson, and A. Simonsson, "Voronoi-Based ISD and Site Density Characteristics for Mobile Networks," In 2012 IEEE Vehicular Technology Conference (VTC Fall), 2012, pp. 1-5, doi: 10.1109/VTCFall.2012.6399149.

[21] A. Akinbolati and M.O. Ajewole, "Investigation of Path Loss and Modeling for Digital Terrestrial Television over Nigeria" Heliyon, vol. 6, no. 6, 2020, doi: 10.1016/j.heliyon.2020.e04101.

[22] A. Ikpehai et al., "Low-Power Wide Area Network Technologies for Internet-of-Things: A Comparative Review," in IEEE Internet of Things Journal, vol. 6, no. 2, pp. 2225-2240, 2019, doi: 10.1109/JIOT.2018.2883728.

[23] M. Stusek et al., "Accuracy Assessment and Cross-Validation of LPWAN Propagation Models in Urban Scenarios," IEEE Access, vol. 8, pp. 154625-154636, 2020, doi: 10.1109/ACCESS.2020.3016042.

[24] P. D. P. Adi and A. Kitagawa, "A performance of radio frequency and signal strength of LoRa with BME280 sensor," Telecommunication Computing Electronics and Control (TELKOMNIKA), vol 18, no. 2, pp. 649-660 2020, doi: 10.12928/telkomnika.v18i2.14843 
[25] S. Tabbane, "IoT Network Planning." https://www.itu.int/en/ITU-D/Regional-Presence/AsiaPacific/SiteAssets/Pages/Events/2016/Dec2016-IoT (accessed Dec 6, 2021)

[26] B. P. Statistik, "Telecommunication Tower Data." 2019. [Online]. Avaliable: http://data.bandung.go.id/dataset/cc83fd7f-eb7b41e8-804a-65d2bb7a9060/resource/567cc18b-7902-43bd-bb54-1d75bee7f322/download/data-menara-telekomunikasi-2019.csv.

\section{BIOGRAPHIES OF AUTHORS}

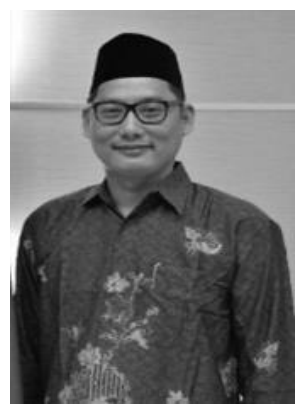

Muhammad Imam Nashiruddin (iD IS SC P earned his bachelor's degree in Electrical Engineering (telecommunication) from University of Brawijaya in 1997, master's degree in Electrical Engineering (Information Technology \& Multimedia System) from Bandung Institute of Technology in 2003 and Ph.D. in business management from Padjajaran University in 2014. His research interest including technology \& engineering management, telecommunication management, telecommunication policy \& regulatory, strategic management of technological innovation, ICT business management and digital transformation. Currently, he is an assistant professor at Telkom University, Indonesia and the Chief of Peruri Research Institute for Authenticity (PRIfA), the research institute of the indonesian government security printing and minting corporation. Previously, he was the Commissioner for Economics and Business at the Indonesian Telecommunications Regulatory Authority (BRTI). He also had experienced as a professional for 17 years at INDOSAT, a Network Service Provider, with his position as Group Head of Corporate Strategy \& Insight. He can be contacted at email: imamnashir@telkomuniversity.ac.id.

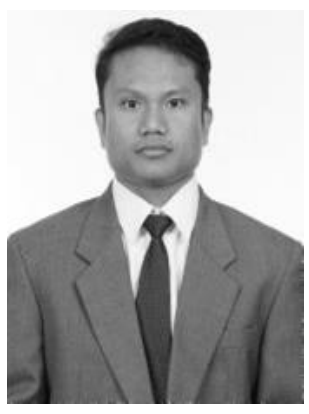

Maruli Tua Baja Sihotang (D) SI SC P received the Bachelor of Engineering in physics from Telkom University, Indonesia, and the Master of Engineeing in electrical engineering, majoring telecommunication management and regulation from Telkom University, Indonesia. His research area mainly consists of network planning, internet of things (IoT), and low power wide area network (LPWAN) technologies. He can be contacted at email: marulisihotang@student.telkomuniversity.ac.id.

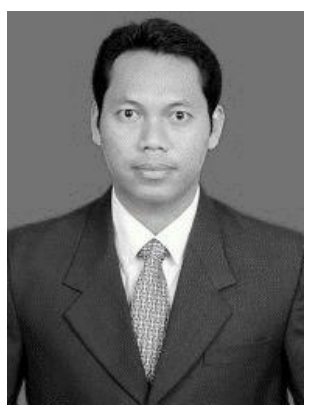

Muhammad Ary Murti (D) SC P graduated from Universitas Brawijaya in 1998 in Bachelor's degree of Electrical Engineering, then received his Master of Engineering degree in instrumentation and control from Bandung Institute of Technology in 2004, and earned his Doctoral degree in instrumentation and control from Bandung Institute of Technology in 2017. He joined STT Telkom (currently Telkom University) in 1998 as a lecturer and since then has worked in different positions at STT Telkom, including coordinator at the Electrical Measurement Lab, head of the Electronic System Laboratory, Control and Industrial Automation Laboratory, and head of the Undergraduate Program (2007-2011). In addition, he was involved in many conferences, such as WOCN2007 Singapore, WOCN2008 Surabaya, ICCSII2012, TIME-e2013, APCC2013, and more. He has been an IEEE member since 2005 and is a member of the IEEE Communication Society, the IEEE Control System Society, and the IEEE Robotics and Automation Society. His research interests include electrical, control, and industrial automation. Currently, he is working on networked control systems, cellular M2M, and the internet of things (IoT). He can be contacted at email: arymurti@telkomuniversity.ac.id. 